\title{
Use of Thallium-201 Myocardial Scintigraphy for the Prediction of the Response to $\beta$-Blocker Therapy in Patients With Dilated Cardiomyopathy
}

\author{
Yuji Hara, MD; Mareomi Hamada, MD; Tomoaki Ohtsuka, MD; Akiyoshi Ogimoto, MD; \\ Hideyuki Saeki, MD; Jun Suzuki, MD; Tsuyoshi Matsunaka, MD; \\ Shigeru Nakata, RT*, Yuji Shigematsu, MD
}

\begin{abstract}
This study was performed to evaluate whether thallium-201 myocardial scintigraphy (Tl-201) and iodine-123metaiodobenzylguanidine (MIBG) myocardial scintigraphy could predict the usefulness of $\beta$-blocker therapy in patients with dilated cardiomyopathy (DCM). Tl-201 and MIBG were performed in 47 patients before $\beta$-blocker therapy. Patients were classified into group A, if their cardiac function improved, and group B, whose function remained unchanged. Two types of extent score (ES) by Tl-201 were proposed to quantitate myocardial damage, mean-2SD (ES-2) and mean-3SD (ES-3). The ES difference between ES-2 and ES-3 was calculated, and according to ES and ES difference, DCM cases were classified into 3 groups: mild-defect type (mild-type), moderate-defect type (moderate-type) and severe-defect type (severe-type). The heart-to-mediastinum (H/M) MIBG uptake ratio was evaluated, and the percent washout ratio of myocardial MIBG was obtained from these data. Group A comprised 18 mild-type, 14 moderate-type and 1 severe-type cases, and group B comprised 5 mild-type, 4 moderate-type and 5 severe-type cases. A significant relation was observed between the defect type on Tl-201 and the response to $\beta$-blocker therapy $(\mathrm{p}=0.0090)$. Both H/M MIBG uptake ratios and washout ratio were not significantly different in the 2 groups. Tl-201 may be useful for predicting the response to $\beta$-blocker therapy in patients with DCM. (Circ J 2002; 66: 1139-1143)
\end{abstract}

Key Words: $\beta$-blocker; Dilated cardiomyopathy; MIBG; Scintigraphy; Thallium

$\mathbf{I}$

n 1975, Waagstein et al reported for the first time that patients with severe heart failure showed clinical improvement after the administration of $\beta$-blocker, and since then the beneficial effect of $\beta$-blocker therapy in patients with chronic congestive heart failure has been confirmed in many studies ${ }^{2-7}$ However, some patients with chronic heart failure show little response to $\beta$-blocker therapy and therefore predicting whether patients with heart failure will respond favorably to the therapy is important.

A few recent studies have reported that iodine-123metaiodobenzylguanidine (MIBG) myocardial scintigraphy may be useful for predicting the outcome of $\beta$-blocker treatment for heart failure?-10 Other reports document the usefulness of thallium-201 (Tl-201) myocardial scintigraphy for predicting prognosis for patients with dilated cardiomyopathy (DCM)!11,12 In the present study, we examined if Tl-201 scintigraphy or MIBG scintigraphy can predict a good response to $\beta$-blocker therapy in patients with DCM.

(Received April 24, 2002; revised manuscript received August 9, 2002; accepted September 12, 2002)

The Second Department of Internal Medicine, Ehime University School of Medicine and *The Department of Radiology, Ehime University School of Medicine, Ehime, Japan

Mailing address: Yuji Hara, MD, The Second Department of Internal Medicine, Ehime University School of Medicine, Shigenobu-cho, Onsen-gun, Ehime 791-0295, Japan. E-mail: yujihara@m.ehime-u. ac.jp

\begin{abstract}
Methods
Study Population

Patients were considered eligible for the study if they had symptomatic heart failure for more than 3 months and they had a left ventricular fractional shortening less than $25 \%$. In addition, study patients had to be clinically stable under the standard therapy of digoxin, diuretics, and angiotensinconverting enzyme inhibitor. The study population consisted of 47 patients (mean age, 54 \pm 14 years; 38 men, 9 women). All patients were diagnosed as having DCM according to the criteria of the World Health Organization/International Society and Federation of Cardiology definition of cardiomyopathies $!^{13}$ Patients were excluded if they had obstructive lung disease, asthma or symptomatic peripheral vascular disease. All patients participated in the present study after giving informed consent.
\end{abstract}

\section{Echocardiographic Study}

In all patients, M-mode and 2-dimensional echocardiographic studies were performed with an Aloka SSD 870 or SSD 9000 imaging system (Tokyo, Japan) with 2.5- or 3.5$\mathrm{MHz}$ transducers. The M-mode echocardiogram was recorded on a strip-chart recorder at a paper speed of $50 \mathrm{~mm} / \mathrm{s}$ or $100 \mathrm{~mm} / \mathrm{s}$. From the M-mode echocardiographic study, the following conventional variables were measured according to the criteria of the American Society of Echocardiography 14: left ventricular dimension at end-diastole (LVDd) and end-systole (LVDs). Left ventricular volume was calculated with Teichholtz's formula, and the ejection fraction (EF) was determined. At the time of the echocar- 


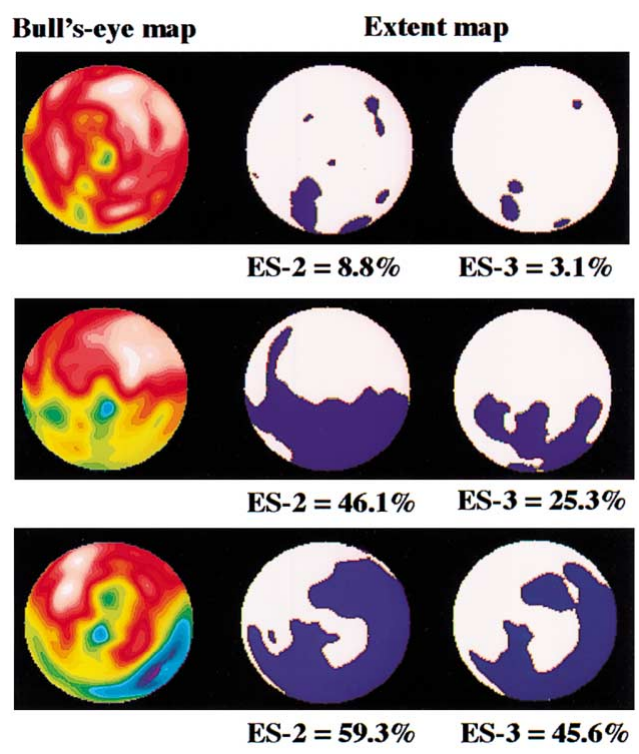

Fig 1. Bull's-eye maps (Left column) and extent maps (Middle column, ES-2; Right column, ES-3) show the defined mild-type, moderate-type and severe-type (Upper row, mild-type; Middle row, moderate-type; Lower row, severe-type). Extent score (ES) difference is $5.7 \%$ for mild-type, $20.8 \%$ for moderate-type and $13.7 \%$ for severe-type.

diographic study, arterial blood pressure was determined in duplicate via cuff sphygmomanometer.

\section{Thallium-201 Myocardial Scintigraphy and the Determination of Extent Score}

Tl-201 scintigraphy at rest was performed in all patients with DCM, using a method described previously 15 Briefly, subjects were examined in the morning after an overnight fast. Imaging at rest was begun 10 min after administration of $111 \mathrm{MBq}$ of thallium-201, and the imaging was repeated $5 \mathrm{~h}$ later. The single photon emission computed tomography (SPECT) system (GCA 9300; Toshiba, Tokyo, Japan; and Scintipac 2400; Shimadzu, Kyoto, Japan) consisted of a triple-head, digital gamma camera equipped with highresolution, low-energy, parallel-hole collimators. A scintillation camera was rotated for $90 \mathrm{~s}$ for each of 36 projections over $360^{\circ}$ circular orbits. Energy discrimination was provided by a $15 \%$ window centered on the $72 \mathrm{keV}$ photopeak of thallium-201. A series of each 3.5-mm-thick slices was reconstructed with filtered backprojection by a ramp filter. Attenuation correction was made by uniform correction of the Chang method to multiply the original reconstructed image by the correction matrix; ${ }^{16}$ scatter correction was also made.

The computerized thallium-201 tomographic method proposed by Garcia et al ${ }^{17}$ was used to quantify the size of myocardial perfusion defects. A polar map was formulated by comparing the normalized maximal count value at each point with the normal value at the corresponding point. To depict 2 kinds of extent polar map, we selected 2 kinds of lower normal limits, mean-2SD and mean-3SD. The extent score (ES) was defined as the number of points that fell below the lower normal limits and was expressed as a percentage of the total left ventricular points on the extent polar map 18 We named these 2 kinds of extent score ES-2 and ES-3, respectively. In order to quantitate the size of mild to moderate myocardial perfusion defects, the ES
Table 1 Clinical Characteristics of the 2 Groups

\begin{tabular}{lcc}
\hline \hline & $\begin{array}{c}\text { Group A } \\
(n=33)\end{array}$ & $\begin{array}{c}\text { Group B } \\
(n=14)\end{array}$ \\
\hline Mean Age (years) & $53 \pm 15$ & $55 \pm 11$ \\
Sex $($ M/F) & $25: 8$ & $13: 1$ \\
NYHA functional class $(n)$ & & \\
I & 2 & 3 \\
II & 24 & 8 \\
III & 7 & 3 \\
Concomitant medications $n(\%)$ & $31(94 \%)$ & $12(86 \%)$ \\
Furosemide & $23(70 \%)$ & $6(43 \%)$ \\
Spironolactone & $17(52 \%)$ & $9(64 \%)$ \\
Digoxin & $32(88 \%)$ & $13(93 \%)$ \\
ACEI or AII type 1 receptor antagonist & $7(21 \%)$ & $4(29 \%)$ \\
Atrial fibrillation $(n)$ & $47 \pm 49$ & $75 \pm 98$ \\
ANP & $103 \pm 103$ & $188 \pm 202$ \\
BNP & & \\
\hline
\end{tabular}

NYHA, New York Heart Association; ACEI, angiotensin converting enzyme inhibitor; AII, angiotensin II; ANP, atrial natriuretic peptide; BNP, brain natriuretic peptide.

difference between ES-2 and ES-3 was calculated in each case. Patients were classified according to the degree of ES-2 and ES difference: mild-defect type (mild-type) was defined as one with ES- $2<26 \%$ (the basis of the median value of ES-2), moderate-defect type (moderate-type) was defined as one with ES-2 $\geq 26 \%$ and ES difference $\geq 14 \%$ (the basis of the median value of ES difference) and severedefect type (severe-type) was defined as one with ES-2 $\geq 26 \%$ and ES difference $<14 \%$ (Fig 1).

\section{Iodine-123-Metaiodobenzylguanidine Myocardial Scintigraphy}

MIBG scintigraphy was performed in 41 of the 47 patients. On the day of imaging, patients were instructed not to have breakfast and to continue fasting until the end of the last imaging session. Iodine-123-metaiodobenzylguanidine (111 MBq) was intravenously administered, and myocardial SPECT images were obtained at $15 \mathrm{~min}$ (early image) and $5 \mathrm{~h}$ (delayed image) after administration. The SPECT system was the same as that used for Tl-201 scintigraphy. Energy discrimination was provided by a $15 \%$ window centered on the $160 \mathrm{keV}$ photopeak of iodine- 123 . A series of each 3.5-mm-thick slices was reconstructed under the same conditions described for Tl-201 scintigraphy. The polar map for MIBG scintigraphy was determined in the same way as for Tl-201 scintigraphy.

For quantitative analysis of the myocardial iodine-123metaiodobenzylguanidine accumulation, anterior planar projection images were acquired in the SPECT studies. A region of interest (ROI) was selected to encompass the whole heart, and a square ROI, usually $10 \times 10$ pixels in size, was selected to include the mediastinum on both the early and delayed images. The counts per pixel were measured for each ROI, and the heart-to-mediastinum (H/M) iodine-123-metaiodobenzylguanidine activity ratio was calculated. The activity of iodine-123-metaiodobenzylguanidine was corrected by time interval and background, and the myocardial washout rate of iodine-123metaiodobenzylguanidine was determined as the percentage of change in activity from early image to delayed image. The normal range of the myocardial washout rate in our institute was 3-23\%. 
Table 2 Hemodynamics and Cardiac Functional of the 2 Groups During the 6 Months Follow-up

\begin{tabular}{lccccc}
\hline \hline & $H R($ beats $/$ min $)$ & SBP $(\mathrm{mmHg})$ & LVDd (mm) & LVDs $(\mathrm{mm})$ & EF $(\%)$ \\
\hline Group A $(n=33)$ & & & & & \\
$\quad$ Before & $71 \pm 13$ & $116 \pm 13$ & $65 \pm 7$ & $54 \pm 8$ & $35 \pm 10$ \\
$\quad$ After & $64 \pm 7$ & $119 \pm 13$ & $59 \pm 7$ & $45 \pm 8$ & $47 \pm 10$ \\
$\quad$ p value & 0.0004 & 0.2122 & $<0.0001$ & $<0.0001$ & $<0.0001$ \\
Group B $(n=14)$ & & & & \\
$\quad$ Before & $72 \pm 12$ & $113 \pm 12$ & $63 \pm 7$ & $50 \pm 9$ & $42 \pm 12^{\#}$ \\
After & $66 \pm 9$ & $115 \pm 13$ & $62 \pm 6$ & $49 \pm 8$ & $43 \pm 11$ \\
p value & 0.0310 & 0.3262 & 0.0538 & 0.0637 & 0.3084 \\
\hline
\end{tabular}

Values are the mean \pm standard deviation, ${ }^{p} p<0.05$ compared with group $A$. $H R$, heart rate; SBP, systolic blood pressure; LVDd, left ventricular dimension at end-diastole; LVDs, left ventricular dimension at end-systole; EF, ejection fraction.

\section{Measurement of Plasma Concentrations of Atrial and Brain Natriuretic Peptide}

Plasma atrial and brain natriuretic peptide (ANP and BNP) concentrations were determined as reported previously 19 A blood sample was taken from the antecubital vein in the morning after $30 \mathrm{~min}$ of supine rest. Blood was immediately transferred into chilled glass tubes containing disodium EDTA $(1 \mathrm{mg} / \mathrm{ml})$ and aprotinin $(500 \mathrm{U} / \mathrm{ml})$ and centrifuged at $3,000 \mathrm{rpm}$ for $10 \mathrm{~min}$ at $4^{\circ} \mathrm{C}$. The plasma was frozen and stored at $-80^{\circ} \mathrm{C}$ until radioimmunoassay (RIA) was performed for measurement of the plasma concentrations of ANP (Shiono RIA assay kit, Shionogi Co, Ltd, Osaka, Japan) and BNP (S-1215, Shionogi Co, Ltd). At our institution, the normal values are $<43.0 \mathrm{pg} / \mathrm{ml}$ for plasma ANP and $<17.0 \mathrm{pg} / \mathrm{ml}$ for plasma BNP.

\section{$\beta$-Blocker Therapy}

Twenty-two patients were treated with metoprolol, 10 patients were treated with carvedilol and 15 patients were treated with bevantolol. Patients received titrated doses of $\beta$-blockers beginning with a low value of 2.5 or $5 \mathrm{mg}$ and increasing gradually to the maximal dose determined by one of three end points, which were either a decrease in systolic blood pressure to less than $90 \mathrm{mmHg}$, a decrease in heart rate (HR) at rest to less than 50 beats/min, or clinical deterioration. Mean maintenance doses were $39 \pm 15 \mathrm{mg}$ (from $15 \mathrm{mg}$ to $70 \mathrm{mg}$ ) for metoprolol, $13 \pm 3 \mathrm{mg}$ (from $10 \mathrm{mg}$ to $20 \mathrm{mg}$ ) for carvedilol and $55 \pm 25 \mathrm{mg}$ (from $20 \mathrm{mg}$ to $120 \mathrm{mg}$ ) for bevantolol. Under the same standard therapy, all patients were treated with $\beta$-blocker for 6 months.

Echocardiographic studies were performed before and 6 months after treatment. Patients were classified into group A $(n=33)$, if their LVDd decreased by $5 \mathrm{~mm}$ or more or the EF improved by $5 \%$ or more with $\beta$-blocker therapy, and group $B(n=14)$, for those whose LVDd change was less than $5 \mathrm{~mm}$ and $\mathrm{EF}$ change was less than $5 \%$ ?

\section{Statistical Analysis}

Data are presented as mean \pm S.D. Baseline characteristics, except for ANP and BNP, were analyzed with an unpaired $\mathrm{t}$ test or chi-square test (for nonparametrically distributed values). Between group differences in ANP and BNP were tested by Wilcoxon signed rank test. The relationship between the defect type and response to $\beta$-blocker therapy was analyzed by chi-square test. Multivariate logistic regression analysis was performed to determine independent predictors of response to $\beta$-blocker therapy. All calculations were performed on a personal computer with the statistical package StatView (Abacus, Concepts, Inc, Berkeley, CA, USA 1994). A value of $p<0.05$ was consid-
Table 3 Tl-201 and MIBG Scintigraphic Findings of the 2 Groups

\begin{tabular}{lccc}
\hline \hline & $\begin{array}{c}\text { Group A } \\
(n=33)\end{array}$ & $\begin{array}{c}\text { Group B } \\
(n=14)\end{array}$ & p value \\
\hline ES-2 $(\%)$ & $26 \pm 16$ & $33 \pm 19$ & 0.1897 \\
ES-3(\%) & $11 \pm 11$ & $21 \pm 18$ & 0.0282 \\
ES difference $(\%)$ & $15 \pm 7$ & $12 \pm 6$ & 0.2902 \\
Early H/M & $1.78 \pm 0.22$ & $1.82 \pm 0.33$ & 0.6464 \\
Delayed H/M & $1.76 \pm 0.29$ & $1.81 \pm 0.42$ & 0.6321 \\
Washout rate $(\%)$ & $28 \pm 10$ & $27 \pm 11$ & 0.8141 \\
\hline
\end{tabular}

Values are the mean \pm standard deviation. ES, extent score; $H / M$, heart-tomediastinum ratio.

ered significant.

\section{Results}

Clinical Characteristics and Natriuretic Peptides of the 2 Groups at Baseline

When clinical characteristics and natriuretic peptides were evaluated at the start of the study, no significant between-group differences were found in age, sex, New York Heart Association (NYHA) functional class, concomitant medications and number of atrial fibrillations (Table 1). There were also no significant differences in mean dose of concomitant medications of the 2 groups. And finally, ANP and BNP values did not differ significantly between the 2 groups.

\section{Hemodynamics, Cardiac Function, and Tl-201 Scinti- graphic and MIBG Scintigraphic Findings in the 2 Groups}

Table 2 shows the hemodynamics and cardiac function in the 2 groups. Although there were no significant differences in HR, systolic blood pressure, LVDd and LVDs between the 2 groups at the start of the study, EF was significantly greater in group B than in group A. Table 3 shows Tl-201 and MIBG scintigraphic findings in the 2 groups at the start of the study. Although ES-2 and ES difference were not significantly different between the 2 groups, ES-3 was greater in group B than in group A. Early H/M, delayed $\mathrm{H} / \mathrm{M}$ and washout rate were not significantly different between the 2 groups.

\section{Relation Between the Defect Type on Tl-201 Scintigraphy and Response to $\beta$-Blocker}

The relation between the defect type on Tl-201 scintigraphy and response to $\beta$-blocker therapy was examined for the 2 groups at the start of the study. Group A comprised 18 mild-type, 14 moderate-type and 1 severe-type cases, 
Table 4 Independent Predictors of Response to $\beta$-Blocker Therapy

\begin{tabular}{lccc}
\hline \hline & Odds ratio & $\begin{array}{c}95 \% \text { confidence } \\
\text { interval }\end{array}$ & p value \\
\hline Age & 1.010 & $0.964-1.059$ & 0.6669 \\
ANP & 1.006 & $0.996-1.016$ & 0.2463 \\
BNP & 1.020 & $0.999-1.009$ & 0.1020 \\
LVDd & 0.959 & $0.871-1.055$ & 0.3884 \\
LVDs & 0.942 & $0.868-1.022$ & 0.1527 \\
EF & 1.065 & $0.999-1.136$ & 0.0546 \\
ES-2 & 1.025 & $0.988-1.064$ & 0.1897 \\
ES-3 & 1.051 & $1.002-1.102$ & 0.0417 \\
ES difference & 0.948 & $0.861-1.045$ & 0.2852 \\
Mild-type & 0.278 & $0.103-0.748$ & 0.0113 \\
Moderate-type & 1.029 & $0.232-4.559$ & 0.9704 \\
Severe-type & 18.000 & $1.691-191.565$ & 0.0166 \\
Early H/M & 0.961 & $0.119-32.234$ & 0.6374 \\
Delayed H/M & 1.704 & $0.204-14.251$ & 0.6228 \\
Washout ratio & 0.991 & $0.924-1.063$ & 0.8084 \\
\hline
\end{tabular}

$H R$, heart rate; SBP, systolic blood pressure; $L V D d$, left ventricular dimension at end-diastole; LVDs, left ventricular dimension at end-systole; EF, ejection fraction; $E S$, extent score; $H / M$, heart-to-mediastinum ratio.

and group B comprised 5 mild-type, 4 moderate-type and 5 severe-type cases. A significant relation was observed between the defect type on Tl-201 scintigraphy and response to $\beta$-blocker therapy (chi-square $=9.430, p=0.0090$ ).

\section{Logistic Analysis and Probability of Response}

Results of multivariate logistic regression analysis to determine independent predictors of response to $\beta$-blocker therapy are shown in Table 4. Of all the dependent variables, ES-3, mild-type and severe-type remained statistically significant as independent predictors. Among 41 patients with mild-type or moderate-type, 32 patients responded to $\beta$-blocker therapy. With the value of mild-type or moderate-type, the defect type showed a sensitivity of $78 \%$, specificity of $83 \%$ and accuracy of $79 \%$.

\section{Discussion}

In the present study, the defect score and pattern on Tl201 scintigraphy in patients with DCM were associated with a response to $\beta$-blocker therapy. In contrast, the parameters established with MIBG scintigraphy showed no significant relation to the response to $\beta$-blocker therapy.

We previously reported that left ventricular end-systolic wall stress is a potent prognostic variable in patients with $\mathrm{DCM}^{21}$ and in that study, left ventricular end-systolic wall stress and ES of Tl-201 scintigraphy were significantly positively correlated?2 ${ }^{2}$ Doi et al ${ }^{11}$ and Shiotani et al ${ }^{12}$ reported that the severity of Tl-201 perfusion defects in patients with DCM is associated with a poor prognosis. Bukley et $\mathrm{a}^{22}$ indicated that constant perfusion defects seen on thallium scans in patients with DCM might represent areas of myocardial fibrosis and scarring. $\mathrm{Li}$ et $\mathrm{al}^{23}$ also reported a significant relation between perfusion defect on Tl-201 and myocardial fibrosis.

Yamada et $\mathrm{al}^{24}$ demonstrated that patients with mild fibrinogenesis on myocardial biopsy responded to $\beta$-blocker therapy, but those with severe fibrinogenesis did not. They also demonstrated that $\beta$-blocker therapy would be expected to be more effective in patients in whom the dominant type of fibrosis was interfascicular rather than intercellular. Nishi et $\mathrm{al}^{25}$ reported that isoproterenol stress echocardiography predicted the response to $\beta$-blocker therapy in patients with
DCM and they speculated that the severely reduced response to isoproterenol might be because of myocardial damage caused by fibrosis or irreversible degeneration. In our study, the defect score and pattern of Tl-201 were associated with the response to $\beta$-blocker therapy. We think that the area of difference between ES-2 and ES-3 may express the area of mild to moderate myocardial damage. We also think that DCM patients with mild-type or moderate-type are responsive to $\beta$-blocker therapy and Tl-201 may detect reversible damage of the myocardium. We suggest that DCM patients with the mild to moderate type should be treated with $\beta$-blocker.

Some investigators ${ }^{26,27}$ reported that a favorable response occurs in patients with a higher heart rate and more advanced left ventricular dysfunction. However, Eichhorn et $\mathrm{al}^{28}$ and Yamazaki et $\mathrm{al}^{10}$ reported that EF before the administration of $\beta$-blocker did not predict the response to therapy. In our data, patients with a lower EF showed a good response to $\beta$-blocker. Left ventricular variables for predicting the effect of $\beta$-blocker therapy remain controversial in patients with DCM and the exact mechanisms for this remained to be determined. Despite the lack of significant difference in the values of ANP and BNP, these values were less in group A than in group B, which may be related to the response to $\beta$-blocker therapy.

MIBG scintigraphy is considered a useful tool for detecting abnormalities of the myocardial adrenergic nervous system in patients with heart failure?29,30 Recently some studies noted a potential role for MIBG scintigraphy in predicting therapeutic response to $\beta$-blocker in patients with heart failure. Suwa et $\mathrm{al}^{8}$ reported that the $\mathrm{H} / \mathrm{M}$ ratio on the delayed image is a good predictor of response to $\beta$-blocker therapy with a threshold of 1.7 (sensitivity $=91 \%$, specificity $=92 \%$ ). Choi et $\mathrm{al}^{31}$ reported that the washout rate showed a significant inverse correlation with the increase of ejection fraction in patients treated with $\beta$-blocker. Fukuoka et al ${ }^{9}$ and Yamazaki et al ${ }^{10}$, however, observed no difference between responders and non-responders to $\beta$-blocker therapy in terms of washout rate and delayed $\mathrm{H} / \mathrm{M}$ ratio before $\beta$-blocker therapy. In the present study, there was no significant difference between responders and non-responders to $\beta$-blocker therapy in washout rate and delayed $\mathrm{H} / \mathrm{M}$ ratio at the start of the therapy, and MIBG scintigraphy could not predict the response to $\beta$-blocker therapy in patients with DCM. Approximately half of the patients studied by Suwa et $\mathrm{al}^{8}$ were in NYHA functional class IV, but most patients in our study were in NYHA II-III and this difference in NYHA functional class may result in the different results for MIBG in redicting the response to $\beta$-blocker therapy.

\section{Study Limitations}

None of the patients was in NYHA functional class IV at the start of this study, thus it is unclear whether the effect of $\beta$-blocker therapy can be predicted by the defect score and pattern of TL in DCM patients in that functional class. Second, the ES has been established previously, but the definition of defect type is an original idea. However, we think that this method could be distinguish between mild to moderate myocardial perfusion defects and severe myocardial perfusion defects. Third, this study could not investigate the relation between defect type noted on Tl-201 scintigraphy and myocardial pathologic findings. It is not necessarily correct that DCM patients with mild to moderate defect type always have less myocardial fibrosis or less 
myocardial degeneration. The implication of the present data, however, suggests that the more severe the defect score on Tl-201 scintigraphy, the more extensive the myocardial damage. Further study is required in a larger number of DCM patients with severe heart failure to resolve these questions.

\section{Conclusions}

Tl-201 is useful to predict whether patients with DCM will respond to $\beta$-blocker therapy and those DCM patients with a mild to moderate defect-type on Tl-201 should be positively treated with $\beta$-blocker.

\section{References}

1. Waagstein F, Hjalmarson Å, Varnaukas E, Wallentin I. Effect of chronic beta-adrenergic receptor blockade in congestive cardiomyopathy. Br Heart J 1975; 37: 1022-1036.

2. Waagstein F, Bristow MR, Swedberg K, Camerini F, Fowler MB, Silver MA, et al. Beneficial effects of metoprolol in idiopathic dilated cardiomyopathy. Lancet 1993; 342: 1441-1446.

3. Krum H, Sackner-Bernstein JD, Goldsmith RL, Kukin ML, Schwartz B, Penn J, et al. Double-blind, placebo-controlled study of the longterm efficacy of carvedilol in patients with severe chronic heart failure. Circulation 1995; 92: 1499-1506.

4. Packer M, Bristow MR, Cohn JN, Colucci WS, Fowler MB, Gilbert EM, et al. The effect of carvedilol on morbidity and mortality in patients with chronic heart failure. N Engl J Med 1996; 334: 13491355.

5. CIBIS II investigators and committees. The cardiac insufficiency bisoprolol study II (CIBIS-II): A randomised trial. Lancet 1999; 353: 9-13.

6. Sturm B, Pacher R, Strametz-Juranek J, Berger R, Frey B, Stanek B. Effect of beta 1 blockade with atenolol on progression of heart failure in patients pretreated with high-dose enalapril. Eur J Heart Fail 2000; 2: 407-412.

7. Hara Y, Hamada M, Shigematsu Y, Suzuki M, Kodama K, Kuwahara $\mathrm{T}$, et al. Effect of beta-blocker on left ventricular function and natriuretic peptides in patients with chronic heart failure treated with angiotensin-converting enzyme inhibitor. Jpn Circ J 2000; 64: 365 369.

8. Suwa M, Otake Y, Moriguchi A, Ito T, Hirota Y, Kawamura K, et al. Iodine-123 metaiodobenzylguanidine myocardial scintigraphy for prediction of response to $\beta$-blocker therapy in patients with dilated cardiomyopathy. Am Heart J 1997; 133: 353-358.

9. Fukuoka S, Hayashida K, Hirose Y, Shimotsu Y, Ishida Y, Kakuchi $\mathrm{H}$, et al. Use of iodine-123 metaiodobenzylguanidine myocardial imaging to predict the effectiveness of $\beta$-blocker therapy in patients with dilated cardiomyopathy. Eur J Nucl Med 1997; 24: 523-529.

10. Yamazaki J, Muto H, Kabano T, Yamashina S, Nanjo S, Inoue A. Evaluation of $\beta$-blocker therapy in patients with dilated cardiomyopathy-Clinical meaning of iodine-123 metaiodobenzylguanidine myocardial single-photon emission computed tomography. $\mathrm{Am}$ Heart J 2001; 141: 645-652.

11. Doi YL, Chikamori T, Takata J, Yonezawa Y, Poloniecki JD, Ozawa T, et al. Prognostic value of thallium-201 perfusion defects in idiopathic dilated cardiomyopathy. Am J Cardiol 1991; 67: 188-193.

12. Shiotani $H$, Yamabe H, Fukuzaki $H$. The clinical and prognostic significance of dipyridamole Tl-201 emission computed tomography in patients with dilated cardiomyopathy. Jpn Circ J 1987; 51: 10161021.

13. Report of the 1995 World Health Organization/International Society and Federation of Cardiology task force on the definition and classification of cardiomyopathies. Circulation 1996; 93: 841-842.

14. Sahn DJ, DeMaria A, Kisslo J, Weyman A. The Committee on Mmode Standardization of The American Society of Echocardiography:
Recommendations regarding quantitation in M-mode echocardiography: Results of a survey of echocardiographic measurements. Circulation 1978; 58: 1072-1083.

15. Abe M, Hamada M, Matsuoka H, Shigematsu Y, Sumimoto T, Hiwada K. Myocardial scintigraphic characteristics in patients with primary aldosteronism. Hypertension 1994; 23(Suppl I): I-164-I167.

16. Chang LT. A method for attenuation correction in radionuclide computed tomography. IEEE Trans Nucl Sci 1978; NS-25: 638-643.

17. Garcia EV, Van Train K, Maddahi J, Prigent F, Friedman J, Areeda J, et al. Quantification of rotational thallium-201 myocardial tomography. J Nucl Med 1985; 26: 17-26.

18. Gupta NC, Esterbrooks DJ, Hilleman DE, Mohiuddin SM. Comparison of adenosine and exercise thallium-201 single-photon emission computed tomography (SPECT) myocardial perfusion imaging. $J$ Am Coll Cardiol 1992; 19: 248-257.

19. Hamada M, Shigematsu Y, Kawakami H, Minamino N, Kangawa K, Matsuo $\mathrm{H}$, et al. Increased plasma levels of adrenomedullin in patients with hypertrophic cardiomyopathy: Its relation to endothelin-1, natriuretic peptides and noradrenaline. Clin Sci 1998; 94: 21-28.

20. Bristow MR, Gilbert EM, Abraham WT, Adams KF, Fowler MB, Hershberger RE, et al. Carvedilol produces dose-related improvements in left ventricular function and survival in subjects with chronic heart failure. Circulation 1996; 94: 2807-2816.

21. Hara Y, Hamada M, Hiwada K. Left ventricular end-systolic wall stress is a potent prognosis variable in patients with dilated cardiomyopathy. Jpn Circ J 1999; 63: 196-200.

22. Bulkley BH, Hutchins GM, Bailey I, Strauss HW, Pitt B. Thallium 201 imaging and gated cardiac blood pool scans in patients with ischemic and idiopathic congestive cardiomyopathy: A clinical and pathologic study. Circulation 1977; 55: 753-760.

23. Li L, Nohara R, Okuda K, Hosokawa R, Hata T, Tanaka M, et al. Comparative study of ${ }^{201} \mathrm{Tl}$-scintigraphic image and myocardial pathologic findings in patients with dilated cardiomyopathy. Ann Nucl Med 1996; 10: 307-314.

24. Yamada T, Fukunami M, Ohmori M, Iwakura K, Kumagami K, Kondoh N, et al. Which subgroup of patients with dilated cardiomyopathy would benefit from long-term beta-blocker therapy? A histologic viewpoint. J Am Coll Cardiol 1993; 21: 628-633.

25. Nishi I, Iida K, Kawano S, Masumi T, Yamaguchi I. Using isoproterenol stress echocardiography to predict the response to carvedilol in patients with dilated cardiomyopathy. Jpn Circ J 2001; 65: 514518.

26. Engelmeier RS, O'Connel JB, Walsh R, Rad N, Scanlon PJ, Gunnar $\mathrm{RM}$. Improvement in symptoms and exercise tolerance by metoprolol in patients with dilated cardiomyopathy: A double-blind, randomized, placebo-controlled trial. Circulation 1985; 72: 536-546.

27. Anderson JL. Treatment of cardiac myopathies with beta blockers. What do we know, where do we go from here? Postgrad Med 1988; 29: $104-112$.

28. Eichhorn EJ, Heesch CM, Risser RC, Marcoux L, Hatfield B. Predictors of systolic and diastolic improvement in patients with dilated cardiomyopathy treated with metoprolol. J Am Coll Cardiol 1995; 25: $154-162$.

29. Henderson EB, Kahn JK, Corbett JR, Jansen DE, Pippin JJ, Kulkarni $\mathrm{P}$, et al. Abnormal I-123 metaiodobenzylguanidine myocardial washout and distribution may reflect myocardial adrenergic derangement in patients with congestive cardiomyopathy. Circulation 1988; 78: $1192-1199$.

30. Schofer J, Spielmann R, Schuchert A, Weber K, Schlüter M. Iodine123 metaiodobenzylguanidine scintigraphy: A noninvasive method to demonstrate myocardial adrenergic nervous system disintegrity in patients with idiopathic dilated cardiomyopathy. J Am Coll Cardiol 1988; 12: $1252-1258$.

31. Choi JY, Lee K, Hong KP, Kim B, Seo JD, Lee WR, et al. Iodine123 MIBG imaging before treatment of heart failure with carvedilol to predict improvement of left ventricular function and exercise capacity. J Nucl Cardiol 2001; 8: 4-9. 